\title{
The National School on Neutron and X-ray scattering (NX school) at Argonne and Oak Ridge National Lab
}

\author{
U Ruett ${ }^{1}$ \\ ${ }^{1}$ Argonne National Laboratory, Lemont, IL \\ uruett@anl.gov
}

The National School on Neutron and X-ray scattering (NX school) takes place at Argonne and Oak Ridge National Laboratory every summer to educate graduate students from universities and institutes in North America in the use of neutron and X-ray facilities. The School is funded by the U. S. Department of Energy, Office of Science, Basic Energy Sciences, and Materials Sciences and Engineering Division to support the next generation scientists in their research related to physics, chemistry, materials science, geoscience, engineering or related fields. Every year, 60 students are selected and admitted to the school. The students become familiar with state-of-the-art methods lectured by the leading experts in the fields. Researchers from academia, industry, and national laboratories present tutorials on the principles of scattering theory and the characteristics of the sources, as well as lectures on the application of scattering methods to a variety of scientific subjects. The students conduct hands-on short experiments at Argonne's Advanced Photon Source and at Oak Ridge National Laboratory's Spallation Neutron Source and High Flux Isotope Reactor. They will gain experience at a user facility and meet beamline scientists to discuss possible applications for their graduate work. The School is jointly organized and conducted by researchers at Argonne and Oak Ridge National Lab supported by Argonne's Educational Programs and Outreach Division. Due to the COVID-19 outbreak, the 22nd NX School was converted to a virtual format.

Acta Cryst. (2020). A76, a91 